\title{
Ecology of the Western region in Kazakhstan: state and main directions of improvement
}

\author{
Turgai Alimbaev ${ }^{1}$, Zhanna Mazhitova ${ }^{2,}$, Bibizhamal Omarova ${ }^{2}$, Kuralay \\ Yermagambetova $^{3}$, Karlygash Atanakova ${ }^{4}$, and Aiman Zhumanova ${ }^{1}$ \\ ${ }^{1}$ Buketov Karaganda State University, 100028, Universitetskaya str., 28, Karaganda, Republic of \\ Kazakhstan \\ ${ }^{2}$ Astana Medical University, Beybitshilik str., 49A, Nur Sultan, Republic of Kazakhstan \\ ${ }^{3}$ L. N. Gumilyov Eurasian National University, Kanysh Satpayev str., 2A, Nur Sultan, Republic of \\ Kazakhstan \\ ${ }^{4}$ Kazakh National University of Arts, Tauelsyzdyk av., 50, Nur Sultan, Republic of Kazakhstan
}

\begin{abstract}
This article examines the environmental problems of the Western region in the Republic of Kazakhstan. The authors emphasize that for many decades the oil fields of Kazakhstan have developed mainly a raw material management system with extremely high technogenic loads on the environment. It is noted that for Kazakstani economy, oil and gas production and especially their export play a key role in generating income and growth within the gross product. At the same time, the authors point out that the impact of the oil and gas field on the environment in recent years has been characterized by its intensity, diversity and significant scale. The issue of developing new hydrocarbon raw materials deposits is considered, which is accompanied by geological exploration, drilling and construction works, laying of pipelines and roads. The authors come to the conclusion that a strong anthropogenic impact on all components of the environment causes an active change in the chemical and physicochemical properties of the soil, disrupts the hydrological regime of territories, leads to impoverishment and changes in the species composition, structure and productivity of phytocenoses, a reduction in the spatial distribution and number of animal populations. In conclusion, the authors put forward a number of fundamental tasks for solving environmental problems of the industry.
\end{abstract}

\section{Introduction}

The annexation of the Kazakh steppe to the Russian Empire led to the gradual involvement of the region into the sphere of capitalist relations, which made many changes in the socioeconomic life of the population [1]. In particular, new sectors of the economy have developed in Kazakhstan, among which oil production in Western Kazakhstan should be mentioned [2].

*Corresponding author: mazhitova_69@mail.ru 
Western Kazakhstan is one of the developed economic regions in the country. The world's largest developed oil and gas fields are Tengiz, Karachaganak, Kashagan. The region has a unique mineral resource base, i.e., hydrocarbons (oil, gas and gas condensate), reserves of chromium, nickel, titanium, phosphorites, zinc, copper, aluminum and coal. Chemically pure chromium salts based on local raw materials are produced by the Aktobe Plant of Chromium Compounds. JSC Ferrosplav produces metallic chromium and carbonfree ferrochrome. In addition to the main products, it produces calcium carbide, water glass and refractory products. The Atyrau Oil Refinery is increasing its capacity for the production of various brands of gasoline, diesel fuel and other types of products. The Kazakh gas processing plant is located in Zhanaozen. The Aktobe paint and varnish plant, as well as the chemical plant (Alga town), which produces boron, sulfuric and boric acid, and a wide range of mineral fertilizers, continue to expand its production. The largest port in the Caspian Sea should be also noted, i.e., RSE Aktau International Sea Trade Port, as well as a network of river and sea ports - Atyrau, Bautino, Kuryk.

The region has a developed network of oil and gas pipelines of JSC Kaztransoil, JSC KazTransGas, the Caspian Pipeline Consortium, as well as power lines of the unified energy system of Kazakhstan. There are many combined heat and power (CHP) and gas turbine power plants in operation. The presence of rich mineral deposits creates conditions for the growth of the region's economy. The basic industry is the oil and gas industry, which accounts for about $60 \%$ of the industrial potential of the region. Today it is already generally accepted that, at least until the end of the third decade of the XXI century, the oil and gas industry of the Republic of Kazakhstan will be the only driving force that will be able to bring the Kazakhstani economy to the forefront of the world community and ensure fundamental changes in all spheres of life of the republic population. The West of Kazakhstan has long been one of the most promising oil and gas regions. In the western part, practically all hydrocarbon deposits are concentrated, which are at the stage of industrial development. At the moment, in terms of proven oil reserves, Kazakhstan is among the 15 leading countries in the world, and significant reserves of hydrocarbon raw materials account for $3.3 \%$ of the world's reserves [3]. The large-scale development of oil and gas fields characterized by a high content of toxic elements, the presence of the world's largest closed body of water - the Caspian Sea and a number of transit rivers - the Volga, Ural, Emba and others, further aggravated the ecological situation in the region and required more attention in matters of environmental protection.

\section{Materials and methods}

The study is based on the general research principles of historicism and objectivity. Applying these methods in the research enables to consider scientific knowledge as an integral system in which each previous approach indirectly or directly influenced the next one. All this together made it possible to compile a systematic series of scientific and theoretical calculations on the given issue. The views of authors are discussed regardless of ethnocultural preferences and political inclinations, which necessitates a thorough comparison of facts and phenomena in aggregate, that is, a comprehensive study of the problem.

In addition, a systematic approach, which takes into account both the features of the research objects themselves and the factors that determine these features, is used in the paper. Such approaches allow to identify not only gaps in the studied subject, but also some particular aspects of the problem that might not have come to the scholars' attention for one reason or another. In general, this gives the opportunity to objectively compare these aspects and, on their basis, determine the prospects for further research. 


\section{Discussion of the results}

\subsection{Problem statement}

The level of the Caspian Sea was subject to fluctuations and largely depended on the water systems of the rivers feeding it and meteorological conditions. A dangerous hydrological phenomenon was observed here, i.e., wind surges of the waters of the Caspian Sea. Such surges were repeated annually in the spring and autumn months. At the same time, significant areas were exposed to flooding. In addition to the fact that such surges caused great material damage, they were environmentally dangerous. When the territories of oil deposits were flooded, the sea waters were polluted with oil products, which negatively affected the inhabitants of the sea, marine vegetation and microflora. The danger of flooding forced the construction of diversion canals, dams and a number of other expensive protective structures. The Caspian Sea is known for its rich biological resources $-90 \%$ of the world's sturgeon fish stocks are concentrated here. The shallow waters of the Caspian Sea were a nesting place and a stopover for a huge number of waterfowl. The Caspian coast was a resort area of the republic; the Ustyurt reserve was created here. A variety of mineral complexes have been discovered in the region. Their use is fraught with a number of environmental problems. In particular, a feature of the explored Karachaganak gas and oil condensate, Tengiz oil and a number of other oil and gas fields was the high content of hydrogen sulfide and other sulfur compounds, which increased the environmental hazard during their exploitation. The increase in oil and gas production is accompanied not only by an increase in the rate of withdrawal of non-renewable natural resources, but also by the introduction of harmful hydrocarbon pollutants into the environment, among which the most dangerous are crude oil, gas condensates, oil sludge, acid tars and other hazardous substances. As a result of active pollution, there is a change in the chemical and physicochemical properties of the soil, a violation of the hydrological regime of territories, impoverishment and changes in the species composition, structure and productivity of phytocenoses, a reduction in the spatial distribution and number of animal populations. Loss of biological diversity is currently a real environmental threat [4]. Often in the process of violation of the technology of production, transportation and processing of oil, especially during emergencies in which oil and gas emissions occur, there is environmental pollution with oil and oil products, saline formation waters, drilling fluids, chemical reagents, which leads to a violation of environmental balance of natural ecosystems. Practice shows that in Western Kazakhstan there is a process of active development of new hydrocarbon deposits, accompanied by geological exploration, drilling and construction works, laying of pipelines, roads, growth of settlements, which, in turn, has a strong anthropogenic impact on all components of the environment. In other words, all technological processes of oil and gas production and related activities are potential sources of environmental pollution. Particularly it is necessary to analyze the state of the territories adjacent to the places of exploration, development and exploitation of hydrocarbon deposits. $70-80 \%$ of vegetation is destroyed by nearly every drilling rig within a radius of 500-800 meters.

\subsection{Environmental problems of water sources}

The construction and exploitation of wells is accompanied by the destruction of the soil cover by $80 \%$, contamination of the site with oil, drilling fluids and chemicals - by $40 \%$. Soil contamination in some oil fields reaches a thickness of up to 10 meters [5]. It has been proven that, getting into the soil and water, oil brings with it a diverse set of chemical compounds that violate the existing biogeochemical balance in ecosystems: a change in the physical state of the environment, a violation of its water-air regime, the introduction of 
toxic substances, a change in the structure of the soil, a violation of the carbon-nitrogen balance, change in the migration ability of individual microelements in the soil. A dangerous consequence is that the impact of oil on the soil for a long time leads to changes in its microbiological properties. In particular, new specialized forms of microorganisms appear that are capable of oxidizing solid paraffins, gaseous hydrocarbons, and aromatic hydrocarbons. As for higher plants, they die immediately after soil contamination. This is due to the fact that oil is one of the most dangerous pollutants in the biosphere. It is a complex mixture of hydrocarbons and their derivatives, and each of these compounds can be considered as an independent toxicant.

The most severe and dangerous in terms of consequences is the pollution of ground and surface fresh waters, as well as pollution of the marine environment, as is the case in the Caspian Sea. For groundwater and surface water sources, pollutants are usually oil, drilling and oil sludge and waste water. For example, the cuttings formed during well drilling can contain up to $7.5 \%$ oil and up to $15 \%$ organic chemicals used in drilling fluids. In a relatively large volume, sludge often accumulates during oil preparation. In this case, sludge can contain up to $80-85 \%$ oil, up to $50 \%$ mechanical impurities, up to $67 \%$ mineral salts and $4 \%$ surfactants. During the development of oil fields on the shelf, even under normal oil production, each drilling rig throws into the water: oil - 30-120 tons, drill cuttings $-150-400$ tons, drill workings $-200-1000$ tons [6].

At present, about 70-90 thousand tons of oil hydrocarbons are annually supplied to the Caspian Sea with river runoff, and from the coasts -29 thousand tons. A high concentration of oil products is noted throughout the sea mass, especially in its upper layer, and traces of oil have been found in the area more than $800 \mathrm{sq}$. km around offshore drilling platforms. On the region territory, the Caspian oil-producing region, especially the Atyrau and Mangistau regions, is subject to the strongest anthropogenic impact. To date, more than 4.3 million hectares of violated lands have been identified here, including 1.5 million hectares of technogenic zones, 1.9 million hectares of degraded pastures, 0.6 million hectares of contaminated with oil products and 0.3 million hectares of lands with radioactive contamination. The total area of oil pollution in Western Kazakhstan is 194 thousand hectares, and the volume of spilled oil is more than 5 million tons [7]. In general, it can be noted that there is a steady tendency towards the deterioration of the ecological situation in the Caspian basin in all available directions. A significant increase in oil production in recent years has naturally led to a sharp deterioration in the environmental situation in the region. The inclusion at the beginning of the twenty-first century of almost all industrial centers of the western regions of Kazakhstan in the category of districts with an alarming and difficult ecological situation is indicative in this regard. The oil strategy, which is being successfully implemented today in Kazakhstan, has allowed several times to increase oil production not only on land, but also in the Caspian Sea. And as expected, it further increased the risk of contamination of the territory of the republic's water basin with such valuable raw materials as oil. The latter circumstance can lead to a violation of the ecological balance, to the occurrence of man-made emergencies associated with the ignition of oil, oil products, explosions of mixtures of hydrocarbon vapors with air. The main sources of oil pollution in the Caspian Sea are exploration and exploitation of oil fields, transportation of oil products, pollution due to emissions from oil fields, sinking of wells as a result of rising sea water levels and other factors.

The degree of oil pollution in some parts of the sea can exceed the permissible rate by 20 times as a result of oil seepage during production and transportation. Recently, new centers for oil production have been created in Kazakhstan, which, in turn, has negatively affected the ecological state of the region, since the oil produced here contains too much sulfur compounds, as well as mercaptans. Such oil has to be refined in a special way, which 
causes additional problems. When cleaning, it is necessary to take into account environmental standards to prevent pollution of the entire water area of the Caspian.

The ecological problems of the Caspian Sea are associated with periodic changes in its level. In Kazakhstan, about 1200 oil wells remained under water. One of the reasons for the pollution of the Caspian Sea is the wreck of large oil tankers. Along with this, the release of used water during the movement of ships at sea also serves as a source of pollution. The most dangerous source of pollution for the Caspian Sea is emissions containing harmful chemicals, which include hydrocarbons, chlorine organic compounds and heavy metals. The volume of mixed oil products thrown into the sea exceeds the norm by 8 times, and phenols and heavy metals - more than 3 times. One ton of crude oil pollutes a $12 \mathrm{sq} . \mathrm{km}$, as a result of which the biological balance and equilibrium of the basin are disturbed. In the samples taken from the depths of the sea, oil products, phenol, and in some places, mercury were found. Contamination of deep soils has led to a decrease in organisms, and in some places to the disappearance of deep fauna. Pollution of sea waters with oil products leads to disruption of the aeration process, as well as to the destruction of marine fauna and flora.

\subsection{Environmental crisis in the air}

At the same time, the most important components that determine the current general ecological situation are still the real state of the air and water basins, the consumption of water resources. In connection with the rapid development of industry and transport, air pollution, which is a vital part of the natural environment, has become in recent decades one of the most complex environmental problems of our time. Despite the fact that Kazakhstan is not the main supplier of pollutants to the atmosphere in comparison with industrialized countries, according to the Ministry of Environment and Water Resources of the republic at the beginning of the 21 st century, the level of air pollution in cities remained quite high even by world standards. Statistics of the last decade of the twentieth century shows a decrease in emissions of harmful substances into the atmosphere from stationary sources. Nevertheless, the degree of anthropogenic pressure on the natural environment of the Western region remained quite high. In the cities of Western Kazakhstan, a high level of air pollution is noted, and among the pollutants, those generated from oil and gas production and oil refining prevail. For example, air pollution in the Mangistau region is caused by emissions from enterprises mainly related to the oil and gas complex, the chemical, energy and manufacturing industries, the extraction of nonmetallic materials, construction, and also vehicles.

According to the data of the Committee on Statistics, in 2018 the total number of emission sources was 25,625 units (table 1) [8].

Table 1. Number of emission sources for 2018.

\begin{tabular}{|c|c|c|}
\hline \multicolumn{3}{|c|}{ Number of stationary sources of pollutant emissions } \\
\hline Total number (units) & Organized & $\begin{array}{c}\text { Equipped with treatment } \\
\text { facilities }\end{array}$ \\
\hline 25625 & 25625 & 173 \\
\hline
\end{tabular}

According to the Committee on Statistics, the total volume of emissions of harmful substances into the atmosphere in the Mangistau region in 2018 amounted to 65.5 thousand tons.

Emissions data for the main pollutants in the Mangistau region for 2017-2018 are presented in table 2 [9].

RSE "Kazhydromet" monitored the state of atmospheric air in three settlements, i.e., the cities of Aktau, Zhanaozen and the village of Beineu. According to the stationary observation network for 2018, the level of atmospheric air pollution in Aktau and Beineu 
was assessed as high (API=7). Compared to 2017, the level of atmospheric air pollution increased from "increased" to "high". The average concentration of suspended particles (dust) in Aktau was 1.2 MPC daily average, PM-10 suspended particles - 1.0 MPC daily average, ozone (surface) - 1.2 MPC daily average, concentration of other pollutants did not exceed the MPC. In the village of Beineu, the average concentration of suspended particles did not exceed the MPC. In addition, the RSE "Kazhydromet" carried out expeditionary observations of air pollution in the Koshkar-Ata tailing dump and in the Bautino settlement. At the Dunga, Zhetybai deposits and Bautino settlements, the maximum concentrations of suspended solids (PM-10), sulfur dioxide, carbon monoxide, nitrogen dioxide, nitrogen oxide, ammonia, sulfuric acid, and total hydrocarbon did not exceed the MPC. In the city of Aktau, five facts of air pollution by PM-10 suspended particles were recorded. It should be noted that according to the Department of Ecology in the Mangystau region, pollution is of a natural origin.

Table 2. Emissions by main pollutants.

\begin{tabular}{|l|c|c|}
\hline \multicolumn{1}{|c|}{ Contaminants } & 2017 & 2018 \\
\hline Sulfurous anhydride & 1.3 & 1.3 \\
\hline Nitrogen dioxide & 9.6 & 10.3 \\
\hline Solid particles & 3.2 & 3.1 \\
\hline Carbon monoxide & 8.3 & 9.4 \\
\hline Hydrocarbon & 10.85 & 10.88 \\
\hline $\begin{array}{l}\text { Volatile organic } \\
\text { compounds }\end{array}$ & 19.65 & 21.55 \\
\hline
\end{tabular}

\subsection{Environmental problems of water sources}

As noted above, the most severe and dangerous in terms of consequences is the pollution of ground and surface fresh waters, as well as pollution of the marine environment, as in the case of the Caspian Sea, where the main objects of the oil and gas sector of Kazakhstan are concentrated. There are the following surface water bodies on the territory of the Atyrau region: 4 large rivers with a total length of $1002 \mathrm{~km}$ and 9 small rivers with a total length of $348 \mathrm{~km}$, including 7 rivers with a total length up to $10 \mathrm{~km}$ long; $48 \mathrm{~km}$ - up to $200 \mathrm{~km}-2$ rivers with a total length; $300 \mathrm{~km}$ - from 200 to $500 \mathrm{~km}-1$ river $212 \mathrm{~km}$ long; - over 500 $\mathrm{km}-3$ rivers. The main surface water sources of the Atyrau region are the northeastern coast of the Caspian Sea, the Zhaiyk, Uil, Emba, Sagiz rivers, the Kigach, Sharonov delta branches and other small rivers. All rivers of the Atyrau region have a transit flow from the Russian Federation and Aktobe region. The Zhaiyk River (Ural) is the main source of water supply for the Caspian lowland. It originates from the slopes of the South Ural Mountains, crosses the border of Kazakhstan, flows through the territories of the West Kazakhstan and Atyrau regions and flows into the North Caspian. The total length of Zhaiyk is $2534 \mathrm{~km}$, on the territory of Kazakhstan $-1084 \mathrm{~km}$, within the West Kazakhstan region $-761 \mathrm{~km}$. The total area of the river basin is $237,000 \mathrm{~km}^{2}$. The Zhaiyk River forms its flows in the upper part of the basin in the territory of the Russian Federation to the village of Kushum in the West Kazakhstan region, after which the river no longer has any tributaries. Within the West Kazakhstan region, the river receives Chagan, Derkul, Utva, Barbastau tributaries. The Sharonova and Kigash rivers are tributaries and branches of the lower reaches of the Volga River, crossing the territory of Kazakhstan and flowing into the Caspian Sea on the territory of the Atyrau region. The Emba River originates on the western slopes of the Mugodzhar mountains, crosses the territory of the Aktobe and Atyrau regions and is lost among the salty coastal swamps (sors). In the Atyrau region, the actual annual inflow of the main rivers amounted to $13,923 \mathrm{~km}^{3}$ in 2018 . 
The current state of the sewerage networks in Atyrau makes it possible to cover only about $45 \%$ of the urban area and about $30 \%$ of the Balykshi settlement. Water disposal of the right-bank and left-bank parts of the city is carried out by separate sewerage systems. The territory of the city is characterized by a flat relief. The overwhelming majority of pumping stations are in a pre-emergency state. The absence of sewage treatment facilities negatively affects the ecological situation in the area. If in 2017 the volume of wastewater disposal in the region amounted to 18433.91 thousand $\mathrm{m}^{3}$, then in 2018 a decrease in volume was noted -16971.82 thousand $\mathrm{m}^{3}$.

Data on the actual discharges of pollutants and wastewater disposal are presented in table $3[10]$.

Table 3. Pollution of water resources and discharges of pollutants with wastewater.

\begin{tabular}{|c|c|c|c|}
\hline $\begin{array}{c}\text { Information on } \\
\text { the actual } \\
\text { volumes of } \\
\text { discharges }\end{array}$ & & 2017 & 2018 \\
\hline \multirow{2}{*}{$\begin{array}{l}\text { Industrial } \\
\text { discharges }\end{array}$} & $\begin{array}{l}\text { Water disposal volume, } \\
\text { thousand } \mathrm{m}^{3}\end{array}$ & 5010.71 & 6882.507 \\
\hline & $\begin{array}{l}\text { Volume of pollutants, } \\
\text { thousand tons }\end{array}$ & 7.34 & 7.5 \\
\hline \multirow{2}{*}{$\begin{array}{l}\text { Domestic waste } \\
\text { water }\end{array}$} & $\begin{array}{l}\text { Water disposal volume, } \\
\text { thousand } \mathrm{m}^{3}\end{array}$ & 13395.07 & 10089.312 \\
\hline & $\begin{array}{l}\text { Volume of pollutants, } \\
\text { thousand tons }\end{array}$ & 13.9 & 9.27 \\
\hline \multirow{2}{*}{$\begin{array}{l}\text { Emergency and } \\
\text { unauthorized } \\
\text { discharges }\end{array}$} & $\begin{array}{l}\text { Water disposal volume, } \\
\text { thousand } \mathrm{m}^{3}\end{array}$ & 28.12 & 29.1 \\
\hline & $\begin{array}{l}\text { Volume of pollutants, } \\
\text { thousand tons }\end{array}$ & 0.04 & 0 \\
\hline \multirow{2}{*}{$\begin{array}{l}\text { Total (all of the } \\
\text { above } \\
\text { discharges) }\end{array}$} & $\begin{array}{l}\text { Water disposal volume, } \\
\text { thousand } \mathrm{m}^{3}\end{array}$ & 18433.91 & 16971.82 \\
\hline & $\begin{array}{l}\text { Volume of pollutants, } \\
\text { thousand tons }\end{array}$ & 21.9 & 16.8 \\
\hline
\end{tabular}

One of the most dangerous sources of radioactive contamination in the region is the Koshkar-Ata tailing dump located in the Mangistau region. The Koshkar-Ata storage facility for uranium-containing waste from chemical production is the most serious environmental problem in the Western region. It is located at a distance of 7-8 $\mathrm{km}$ from the Caspian Sea and 3-4 km from the regional center. The drainless valley of Koshkar-Ata has been used since 1965 as a storage facility for tailings from three plants of the former giant, the Caspian Mining and Metallurgical Plant: The Chemical Hydrometallurgical Plant (ChHMP), a sulfuric acid plant (SAP) and a nitrogen fertilizer plant (NFP) for warehousing and storing unused solid waste of chemical and mining and metallurgical production. The total volume of accumulated solid waste is 104.8 million tons, including 51.8 million tons of radioactive waste. According to the Ministry of Environmental Protection of the Republic of Kazakhstan, more than 400 million tons of toxic and radioactive waste are stored in the lake, including about 105 million tons of uranium production waste, of which weakly radioactive with a total activity of $11,242.825$ Curie -51.8 million tons. This type of waste is a natural series of uranium-238. The most toxic of them are uranium-238, radium-226, thorium-230 [11]. It is the largest tailing dump for radioactive substances in the world. The composition of the waste placed in it includes substances such as nitrates, 
nitrites, ammonium, iron, phosphates, fluorine, cobalt, nickel, strontium, zinc, copper, chromium, molybdenum, manganese, lead, which lie under a layer of salt water, therefore this reservoir the locals call the "dead lake", where no fish live in, and no birds sit down. The tailings dump area, which is $77 \mathrm{~km}^{2}$, is considered the largest in the world. The total area of the disposed waste is $66 \mathrm{~km}^{2}$. The area of the so-called "beaches" that are bare in the southern part of the lake, at this time, is $51 \mathrm{~km}^{2}$, its average width is $4 \mathrm{~km}$, and its length is $6 \mathrm{~km}$ (measured by satellite image). The process of intensive evaporation and the lack of volumes of incoming wastewater led to the fact that the surface area of the tailings pond decreased by $4.2 \mathrm{~km}$. These numbers will increase as the process of lowering the level of the water phase continues, because the lake has no special isolation from the subsoil, which is why the recharge by sea water has been stopped. Groundwater contamination through underground horizons was noted for $4 \mathrm{~km}$. Many researchers have long stated about the danger of lake waters penetrating into the Caspian Sea, located nearby. The systematic study of the impact of the tailing dump on the environment and population has ceased since the early 1990 s before 2002, i.e. it was interrupted for almost 10 years, during which the tailing dump was degraded as a strictly controlled facility. Since the termination of the activities of PA "Caspian Mining and Metallurgical Combine" ("PGMK"), the tailing dump continued to be used not only as a storage facility for industrial and domestic waste water, but also as a dump for solid domestic waste, which opened free access to the territory of the tailing dump. Due to a decrease in the level of the waste water phase, the tailing dump dried out in places, covered with salt crust and dust (more than 10 years), and the exposed bottom sediments became sources of toxic dust due to the constantly blowing winds. Experts note that toxic dust is easily carried over long distances even in low winds. With an average wind speed in the region of 5-6 m/s and constantly blowing winds from the sea, this dust is carried far into the mainland, polluting the territory of the region. Since 2003, design work began on the reclamation of the bare areas of the tailing dump. However, despite the measures taken, the environmental situation in and around the tailing dump remains rather difficult. The increased content of 205 trace elements indicates deflation of contaminated sandy material and its wind transfer from the bare areas of the tailing dump. As mentioned above, the village of Baskuduk is in the risk zone, which is closest to Koshkar-Ata. The highest concentration of radionuclides was found here. This was shown by studies of the fur of domestic animals, as well as vegetation near the village. In general, the isotope of uranium-238, also called depleted uranium, is a by-product of the enrichment of uranium ore and is one of the strongest general cellular poisons, which, when deposited on skin and lungs when inhaled during dust transfer, causes internal irradiation of the body, especially strongly affecting the kidney and other internal organs on the molecular level associated with the circulation of intercellular fluids [12]. To stabilize the state of the tailing dump and adjacent territories, it is necessary not only to constantly monitor the deflation of radioactive and toxic material, groundwater, but also to take specific measures that require huge financial costs. Lake Koshkar-ata was ignored for a long time. However, now, when the Mangystau region and the vicinity of Aktau are becoming a place for large investment projects and a place for the development of business activity and tourism, the problem of the tailings dump is becoming topical.

At present, it is highly topical to reduce environmental pollution by modernizing the oil and gas sector of the economy using the most effective technologies, ensuring the investment attractiveness of measures for the efficient use of hydrocarbon resources, creating a strategic "reserve" of hydrocarbon raw materials.

The most important task at the present stage of development is the issue of introducing renewable energy sources. It is fundamentally important for Kazakhstan to rethink its attitude to its natural resources. The government must manage them correctly, accumulating revenues from their sale in the treasury, and most importantly, transforming the natural 
resources of our country into sustainable economic growth as efficiently as possible. In the modern period, mankind consumes a huge amount of natural resources, in particular, fuel and energy, among them a special role belongs to oil and gas, which are united by the concept of "hydrocarbon raw materials". The world has a huge number of problems associated with the use of hydrocarbons. They are of a political, economic, social and especially ecological nature. The high and ever-increasing growth of oil production and refining in the world leads to the fact that the level of environmental pollution by oil products is currently acquiring a global character. The Republic of Kazakhstan is no exception. More and more significant territories of Kazakhstan are being drawn into the sphere of anthropogenic development of oil and gas fields, the inevitable consequence of which is the deterioration of the ecological situation. It should be noted that over the course of many decades, a predominantly raw material management system with extremely high anthropogenic loads on the environment has developed in the oil fields of Kazakhstan. At the same time, the impact of the oil and gas field on the environment is intense, diverse and significant. It is clear that for the economy of our country, the extraction and especially the export of oil and gas play a key role in generating income and GDP growth, which means that the extraction of minerals in this region will continue, giving rise to new environmental problems.

\section{Conclusion}

The current ecological state of the territory of Kazakhstan can be defined as critical [13, 14]. Currently, in the Western region of Kazakhstan, under the influence of industrial activities, hundreds of chemical pollutants are simultaneously present in the atmospheric air, which are in complex interaction, which enhances or neutralizes their influence. So, in most water bodies, due to the discharge of untreated and insufficiently treated wastewater of industrial and municipal origin, there is a change in the structure and composition of ichthyofauna and a decrease in fish stocks. Analysis of the industrial development of the Western region of Kazakhstan in the context of environmental problems allows us to identify typical regional reasons for the critical state of the environment, which developed at the beginning of the XXI century. This is a technocratic approach to solving environmental problems, aimed not at radical socio-economic transformations, but calculated on quantitative, superficial changes, which, in particular, only increase the depersonalization of ownership of natural resources, contradictions arising from the inconsistency of imperfect, uneconomic technologies and techniques to the requirements of rational nature management, which may subsequently lead to a nationwide ecological crisis. Irresponsibility and lack of control of the relevant ministries, departments, regional and local self-government bodies, activities of which are often aimed not for the good, but to the detriment of the environment, the lack of sufficient economic interest and responsibility of enterprises and organizations in the implementation of environmental activities, which are currently not integrated with their the main activity, a one-sided consumer approach for the sake of momentary economic interests, the consequence of which is the absence of a promising strategic principle in environmental protection, a low level of environmental culture, education and consciousness of the population. A complex combination of natural and anthropogenic impacts, among which the most significant and problematic industrial impact, serves as the basis for predictions regarding the further aggravation of environmental problems. The task of ecological remediation of this region is multifaceted, but quite feasible. In this regard, the following promising directions for optimizing the state of the natural environment in this region seem to be the most important. 1. Elimination of historical pollution, as well as sources of negative impact on the environment (inactive wells, waste water storage, landfills and other production facilities). 2. Reducing emissions 
into the environment by improving technological solutions, for example, replacing fuel oil with fuel/natural gas (as fuel in technological furnaces), by using new generation additives, replacing equipment, expanding production capacities for gas processing, building of installations for gas processing, etc. It is necessary to improve measures for the protection of atmospheric air through the introduction of treatment facilities and installations. 3 . Reduction of discharges of pollutants through the modernization of wastewater treatment facilities. Improving the efficiency of the use and protection of water resources, including improving the state of small rivers, reservoirs, monitoring the state of groundwater. 4. Solving the problems of rational use of lands, including protection from wind and water erosion, flooding, waterlogging and salinization. An important issue is to reduce the chemical load on the soil.

In these conditions, the priority area of state bodies activity should be the active use of economic, legal and organizational methods of influencing the emerging economic system, its maximum greening in order to balance the development of diverse processes: the economic development of the country and the creation of a favorable environment for human life and health. Technologically, the priority areas of environmental policy at the beginning of the XXI century should be a consistent transition to international environmentally friendly standards of technological processes and manufactured products. In our opinion, there is a need for developments that stimulate the introduction of lowwaste, resource and energy-saving technologies, processes based on the achievements of scientific and technological progress, the intensification of research and development work, investment projects of an environmental focus. Particular attention should be paid to the greening of the consciousness of users of natural resources and the formation of an appropriate public opinion, since the changes taking place in the world necessitate the formation of a holistic humanistic worldview towards the nature, in which universal human values will receive priority.

\section{References}

1. Zh.S. Mazhitova, Place and Role of the Biy Council and People's Assembly in the Traditional Kazakh Society of the XVIII-XIX Centuries (Following the Data of the PreRevolutionary Russian Historiography), Asian Social Science 10, 20, 129-136 (2014)

2. History of Kazakhstan (from ancient times to the present day), In five volumes, Almaty: Atamura 3, 768 (2000)

3. Oil and gas 4, 19 (2014)

4. O.I. Yegorov, O.A. Chigarkina, A.S. Baimukanov, Oil and Gas Complex of Kazakhstan: Development Problems and Operational Efficiency, Almaty: Atamura 536 (2003)

5. A.A. Abrosimov, M.Yu. Dolomatova, E.G. Telyasheva, Ecology of processing of hydrocarbon systems, Moscow: Chemistry 81 (2002)

6. Yu.A. Podavalov, Ecology of oil and gas production, Moscow: Infra-Engineering 146 (2010)

7. Oil and gas, Strategic goals of NC KazMunayGas 16 (2017)

8. National report on the state of the environment and the use of natural resources of the Republic of Kazakhstan for 2018, Astana 355 (2019)

9. National report on the state of the environment and the use of National report on the state of the environment and the use of natural resources of the Republic of Kazakhstan for 2018, Astana, 356 (2019) 
10. National report on the state of the environment and the use of natural resources of the Republic of Kazakhstan for 2018, Astana, 315 (2019)

11. Kazmunai gas annual report for 2019, Astana, 163 (2019)

12. A.G. Koshim, A.S. Akashova et al. Koshkar-Ata tailing dump is a source of processes of radiative salt formation and dust transfer (ecological analysis). Bulletin of KazNU 38, 204 (2013)

13. T. Alimbaev, B. Omarova, B. Abzhapparova, K. Ilyassova, K. Yermagambetova, Zh. Mazhitova, Environment of East Kazakhstan: State and main directions of optimization, E3S Web of Conferences 175, 1-8 (2020)

14. T. Alimbaev, Zh. Mazhitova, Ch. Beksultanova, N. Tentigul Kyzy, Activities of mining and metallurgical industry enterprises of the Republic of Kazakhstan: environmental problems and possible solutions, E3S Web of Conferences 175, 1-9 (2020) 